\title{
MODE OF ACTION OF TARSORRHAPHY IN NEUROPARALYTIC KERATITIS*
}

\author{
BY \\ P. SIVASUBRAMANIAM \\ Victoria Memorial Eye Hospital, Colombo, Ceylon
}

LITTLE is known about the mode of action of tarsorrhaphy in neuroparalytic keratitis, though this simple operation is followed by a dramatic improvement, sometimes in a matter of hours. Neuroparalytic keratitis may result from diverse causes, the common factor being a lesion of the trigeminal ganglion.

The theory of the causation of neuroparalytic keratitis propounded by Duke-Elder (1938) is based on Loewi's triple response, the corneal changes being due to an accumulation of metabolites which initiate tissue oedema and vasodilatation. The oedema then leads to impaired vitality, degeneration, and exfoliation of the corneal epithelium.

In this paper based on clinical observations made in the Eye Clinic of the Jaffna General Hospital and in the Leprosarium, Hendala, a tentative explanation is offered of the mode of action of tarsorrhaphy in neuroparalytic keratitis.

\section{Material}

Case 1. Excision of a left parotid tumour in a man aged 52 resulted in left facial palsy, and infiltration of the nasopharynx and orbit had led to left total ophthalmoplegia when the patient was first seen, and 4 months later neuroparalytic keratitis developed. The left ptosis did not prevent the onset of corneal ulceration. The patient refused a tarsorrhaphy and the left eye was lost owing to progressive ulceration of the cornea.

Case 2. A nasopharyngeal endothelioma on the right side in a man aged 48 led to total ophthalmoplegia and proptosis. The neuroparalytic keratitis which followed was cured by tarsorrhaphy.

Case 3. A nasopharyngeal tumour on the right side in a man aged 50 left him with an intact cornea, but neuroparalytic keratitis followed in 6 months' time. Tarsorrhaphy cured the keratitis, although ophthalmoplegia and proptosis were present when he was first seen.

Case 4. Congenital deficiency of the fifth nerve in a woman aged 48 led to bilateral neuroparalytic keratitis with an interval of a year between the onset in the two eyes. Tarsorrhaphy cured the condition.

Case 5. Generalized herpes with neuroparalytic keratitis of the right eye in a man aged 45 was not affected by plain bandaging, antihistamines, or cortisone with oxytetracycline, and wearing a contact lens (for 48 hours) made the condition worse. Finally tarsorrhaphy cured the ulceration.

Case 6. Trigeminal neuralgia in a man aged 45 , and alcohol injection of the trigeminal

* Received for publication April 18, 1957. 
ganglion was followed by neuroparalytic keratitis. He refused tarsorrhaphy, and when he was seen 10 years later the cornea had healed with a faint scar and there were traces of old iritis. The cornea as well as the lids were anaesthetic.

Cases 7, 8, and 9. Vesiculation of corneal grafts was healed by tarsorrhaphy.

Case 10. Fuchs's dystrophy in a woman aged 52 was relieved by tarsorrhaphy.

Case 11. Recurrent corneal erosion in the right eye in a man aged 50 was relieved by tarsorrhaphy.

Case 12. In leprous keratitis of the neuropathic type in the right eye in a man aged 55 , the ulceration was healed by tarsorrhaphy.

Case 13. Acute keratoconus occurred in a boy aged 18; pressure bandaging (after the method of Terry and Chisholm, 1940) effected rapid relief of symptoms and the cone receded (Sivasubramaniam, Hoole, and Anandarajan, 1953).

Cases 1, 2, and 3 developed neuroparalytic keratitis in spite of coexisting ptosis. Case 1 refused tarsorrhaphy and lost the affected eye, but in the other two cases the eyes were saved by tarsorrhaphy.

In Case 5, antihistamines, cortisone with oxytetracycline, and splinting with a contact lens had no effect, but tarsorrhaphy eventually effected a cure.

\section{Discussion}

According to Paton (1926), involvement of the trigeminal nerve "seemingly in any part of its course" may lead to neuroparalytic keratitis. Paton believed that "there must be a central element in its causation" and that "protecting the eye by sewing the lids together invariably results in preventing the development of the condition or in the rapid cure of the condition if it has developed, which would seem to indicate almost equally definitely that there must be a peripheral element in its causation".

It must be recalled that the mere absence of nerve supply to the cornea is insufficient, as in cataract extraction and in penetrating keratoplasty neuroparalytic keratitis does not develop though corneal oedema may develop as a result of loss of sensation (Sarwar, 1953). It is striking too that the rest of the distribution of the fifth nerve does not exhibit any lesions in neuroparalytic keratitis and a tarsorrhaphy heals remarkably well despite anaesthesia of the skin. From the foregoing it appears that avascularity of the cornea renders it peculiarly susceptible to neuropathic keratitis. The peripheral element referred to by Paton is what Duke-Elder refers to as a loss of peripheral control over the metabolic activity of the cornea.

Basing the probable aetiology of neuroparalytic keratitis on Duke-Elder's theory, it is the writer's view that tarsorrhaphy acts as a splint to the cornea and supports it, while the movements of the globe behind such a splint helps to massage the cornea and expedite the removal of stagnant metabolites and thus reduce tissue oedema. A ptosed lid, while excluding trauma and desiccation, allows neuroparalytic keratitis to develop because it hangs limply like a curtain over the cornea and is not close enough to act as a splint. Even in the presence of proptosis, a ptosed lid does not function in 
the manner described unless it is sewn to the lower lid, when the bulge of the eye makes the sewn lids a little taut and thus more effective even if the globe is immobile and the lids atonic.

Drawing a parallel from general medicine, supportive bandaging of an injured joint discourages oedema round it. Supportive bandaging of an eye may likewise reduce corneal oedema as in Case 13. In fact, early bandaging may avert an impending case of neuroparalytic keratitis, but this method has its limitations, because of the frequent changes necessitated.

A contact lens may afford protection to an anaesthetic cornea as after trigeminal ganglion injection (Ridley, 1954; Sarwar, 1953), though some doubt has been cast on its value in cases of established neuroparalytic keratitis (Williamson-Noble, 1953). If a contact lens is to act as a splint, as it must if it is to be of benefit in neuroparalytic keratitis, it must fit closely with only a hypothetical tear film between it and the cornea. The failure of the contact lens to produce satisfactory results in Case 5 is understandable though it has its place in exposure keratitis where the nerve supply to the cornea is intact.

Antihistamines including cortisone are probably ineffective because neuroparalytic keratitis is not an allergic manifestation.

The disappearance of vesiculation in cases of recurrent corneal erosion, herpes zoster of the cornea, and keratoplasty (Cases 7, 8, and 9) supports the view that the value of tarsorrhaphy lies in the splinting and massage which it provides. This would explain the observation that an adhesion only a few millimetres broad between the lids in a case of neuroparalytic keratitis may turn the tide in favour of the patient.

Segall (1955), discussing the problem of congenital deficiency of the fifth nerve, asserts that exposure seems to be an integral factor in the development of keratomalacia and neuroparalytic keratitis, since the ulceration occurs in the exposed areas of the cornea. It is the writer's view that the exposed areas are affected in neuroparalytic keratitis because of the lack of support of the cornea. Tarsorrhaphy may therefore be considered an emergency stop-gap measure to save not merely the cornea but the whole eye until such time as a readaptive mechanism comes into play, and a humoral control begins to operate in place of the nervous control.

My thanks are due to the Medical Officer-in-Charge, Government General Hospital, Jaffna, and to Dr. P. J. de Fonseka, Superintendent of the Leprosarium, Hendala, Ceylon, for granting me permission to publish the cases described in this paper.

\section{REFERENCES}

DUKe-Elder, S. (1938). “Text-book of Ophthalmology", vol. 2, p. 1956. Kimpton, London. Paton, L. (1926). Brit. J. Ophthal., 10, 305.

RIDLEY, F. (1954). Trans. ophthal. Soc. U.K., 74, 377.

SARWAR, M. (1953). Ibid., 73, 547

Segall, W. (1955). Amer. J. Ophthal., 39, 732.

Sivasubramaniam, P., Hoole, T., and ANANDARajan, S. (1953). Cey. med. J., $2,129$.

Terry, T. L., and Chisholm, J. F., (1940). Amer. J. Ophthal., 23, 1089.

WIILIAMSON-NOBLE, F. A. (1953)." Trans. ophthal. Soc. U.K., 73, 552. 